\title{
Solid tumor size for prediction of recurrence in large and giant non-functioning pituitary adenomas
}

\author{
Ching-Chung Ko ${ }^{1,2}(\mathbb{1}) \cdot$ Chin-Hong Chang ${ }^{3} \cdot$ Tai-Yuan Chen ${ }^{1,4} \cdot$ Sher-Wei Lim ${ }^{5,6} \cdot$ Te-Chang Wu $^{1,4} \cdot$ Jeon-Hor Chen ${ }^{7,8}$. \\ Yu-Ting Kuo ${ }^{1,9}$
}

Received: 1 June 2021 / Revised: 16 September 2021 / Accepted: 29 September 2021 / Published online: 4 October 2021

(c) The Author(s) 2021, corrected publication 2021

\begin{abstract}
A subset of large non-functioning pituitary adenomas (INFPA) and giant non-functioning pituitary adenomas (gNFPA) undergoes early progression/recurrence $(\mathrm{P} / \mathrm{R})$ after surgery. This study revealed the clinical and image predictors of P/R in 1 NFPA and gNFPA, with emphasis on solid tumor size. This retrospective study investigated the preoperative MR imaging features for the prediction of P/R in INFPA $(>3 \mathrm{~cm})$ and gNFPA $(>4 \mathrm{~cm})$. Only the patients with a complete preoperative brain MRI and undergone postoperative MRI follow-ups for more than 1 year were included. From November 2010 to December 2020, a total of 34 patients diagnosed with INFPA and gNFPA were included (median follow-up time 47.6 months) in this study. A total of twenty-three $(23 / 34,67.6 \%)$ patients had P/R, and the median time to P/R is 25.2 months. Solid tumor diameter (STD), solid tumor volume (STV), and extent of resection are associated with P/R $(p<0.05)$. Multivariate analysis showed large STV is a risk factor for $\mathrm{P} / \mathrm{R}(p<0.05)$ with a hazard ratio of 30.79. The cutoff points of STD and STV for prediction of P/R are $26 \mathrm{~mm}$ and $7.6 \mathrm{~cm}^{3}$, with AUCs of 0.78 and 0.79 respectively. Kaplan-Meier analysis of tumor P/R trends showed that patients with larger STD and STV exhibited shorter progression-free survival $(p<0.05)$. For INFPA and gNFPA, preoperative STD and STV are significant predictors of $\mathrm{P} / \mathrm{R}$. The results offer objective and valuable information for treatment planning in this subgroup.
\end{abstract}

Keywords Solid tumor size $\cdot$ Pituitary macroadenoma $\cdot$ Recurrence $\cdot$ Non-functioning $\cdot$ MRI

Ching-Chung Ko

kocc0729@gmail.com

1 Department of Medical Imaging, Chi-Mei Medical Center, Tainan, Taiwan

2 Department of Health and Nutrition, Chia Nan University of Pharmacy and Science, Tainan, Taiwan

3 Department of Neurosurgery, Chi Mei Medical Center, Tainan, Taiwan

4 Graduate Institute of Medical Sciences, Chang Jung Christian University, Tainan, Taiwan

5 Department of Neurosurgery, Chi-Mei Medical Center, Chiali, Tainan, Taiwan

6 Department of Nursing, Min-Hwei College of Health Care Management, Tainan, Taiwan

7 Department of Radiological Sciences, University of California, Irvine, CA, USA

8 Department of Radiology, E-DA Hospital, I-Shou University, Kaohsiung, Taiwan

9 Department of Medical Imaging, Kaohsiung Medical University Hospital, Kaohsiung, Taiwan

\section{Introduction}

Pituitary adenomas (PA) constitute $10-25 \%$ of all intracranial neoplasms [12]. A subgroup of these tumors particularly challenging to manage are those that can be classified as large and giant PA [4, 8]. Although there is no consensus regarding the exact definition of tumor size, the largest tumor diameter of $>4 \mathrm{~cm}$ is considered giant, whereas $>3 \mathrm{~cm}$ is considered large $[5,8,19,30,34,38]$. Large and giant PA that grow beyond the sellar are always difficult to manage surgically because of the surrounding important neurovascular structures and a greater risk of complications $[4,8,35]$. Large and giant PA comprise about $6-10 \%$ of all pituitary tumors $[12,44]$. Most of them are clinically non-functioning pituitary adenomas (NFPA) and occur predominantly in males [12, 17, 44]. Visual field defects resulting from compression of optic chiasm are the most common preoperative symptoms followed by a headache. Partial or total hypopituitarism is observed in some patients due to tumor compression of the normal pituitary gland [17]. Although more than $90 \%$ of NFPA are diagnosed as benign adenomas 
according to $2017 \mathrm{WHO}$ classification [27], 12-46\% of them may undergo early progression/recurrence $(\mathrm{P} / \mathrm{R})$ after surgical resection $[6,7,9,13,40]$. Gross-total resection (GTR) by transsphenoidal approach (TSA) is the standard surgical treatment in the majority of NFPA; however, it is difficult to achieve in large NFPA (INFPA) and giant NFPA (gNFPA) [36]. Therefore, a relatively high $\mathrm{P} / \mathrm{R}$ rate due to postoperative residual tumor had been reported in this subgroup $[6,7$, 39]. Although adjuvant radiotherapy (RT) is implemented in some institutions to prevent P/R in NFPA, $20-30 \%$ of patients may have irreversible hypopituitarism or other complications after treatment [17].

MRI findings such as cavernous sinus invasion, absence of apoplexy, postoperative residual tumor, diffusion restriction, and radiomics score have been reported as significant parameters related to P/R in NFPA [21, 28, 46]. However, some of them are qualitative, and others need to be analyzed on advanced MRI sequences. In oncologic imaging, Response Evaluation Criteria in Solid Tumors (RECIST), based on simple one-dimensional morphologic measurement of tumor diameter, is the gold standard for assessment of treatment response in solid tumors [10, 43]. However, a modified RECIST was developed based on the concept that a viable tumor should be defined as only intratumoral enhancing solid mass in some tumors [24, 26]. Although large tumor size is associated with lesser extent of tumor resection and more surgical complications in NFPA [2, 13, $28,36,41]$, the preoperative quantitative tumor size for the prediction of postoperative recurrence in NFPA was rarely mentioned. Further, no reports regarding the concept of simple measurements of solid tumor size for the prediction of clinical outcomes in NFPA have been published as of yet. This study evaluated the preoperative clinical and MR imaging characteristics for the prediction of P/R in INFPA and gNFPA, with emphasis on solid tumor diameter (STD) and solid tumor volume (STV).

\section{Materials and methods}

\section{Ethics statement}

This study was approved by the Institutional Review Board (IRB no. 10902-009). Written consent was waived because the retrospective nature of this study does not influence the health care of the included patients. All patients' medical records and imaging are anonymized and de-identified prior to analysis.

\section{Patient selection}

The inclusion criteria of this study are patients diagnosed with large $(>3 \mathrm{~cm})$ or giant $(>4 \mathrm{~cm})$ NFPA by brain
MRI and pathological confirmation, and with post-operative follow-up MRIs (at least 2 times) more than 1 year after treatment. Patients with clinical, biochemical, or histopathological evidence of hormone hypersecretion are excluded. Diagnosis of prolactinoma is considered unlikely if the prolactin levels are below $100 \mathrm{mg} / \mathrm{L}$ according to previous studies $[2,16]$, and a conclusion thereafter confirmed by immunocytochemical studies. Patients receiving postoperative adjuvant $\mathrm{RT}$ before $\mathrm{P} / \mathrm{R}$ are also excluded. From September 2010 to December 2020, 292 patients are diagnosed with PA in our institution. Thirtyfour patients $(34 / 292,11.6 \%)$ (21 men, 13 women, age 20-80 years; median age, 49.5 years) diagnosed with INFPA and gNFPA are included in this study by the abovementioned inclusion and exclusion criteria. Among them, thirty-two patients underwent surgery performed by TSA, and 2 patients received both TSA and craniotomy due to large tumor sizes. Fourteen $(14 / 34,41.2 \%)$ patients received repeated surgery due to tumor recurrence. The median follow-up duration for all patients is 47.6 months (range from 12 to 115 months). In 23 patients with $\mathrm{P} / \mathrm{R}$, the median time to $P / R$ is 25.2 months (range from 6 to 67 months). Clinical and biochemical data are obtained from medical records.

\section{Extent of resection and progression/recurrence}

The extent of resection (EOR) is determined by reviewing postoperative MRI by a neuroradiologist (C.C.K.) and a neurosurgeon (S.W.L.). According to published literatures $[21,45,46]$, GTR is defined as a lesion with a residual tumor volume of less than $10 \%$ of its original size. In contrast, subtotal resection (STR) is defined as the presence of a residual tumor more than $10 \%$ of its original volume. For determining P/R in the included NFPA patients, pretreatment and postoperative MR images are evaluated by two experienced neuroradiologists (C.C.K. with 7 years of experience and T.Y.C. with 20 years of experience), both of whom are blinded to the clinical outcomes of the studied population. $\mathrm{P} / \mathrm{R}$ is defined as tumor recurrence after GTR or enlargement of residual tumor after STR based on postoperative contrast-enhanced (CE) T1WI. According to published literatures $[2,21,46]$, the threshold of $\mathrm{P} / \mathrm{R}$ is defined as a more than $2-\mathrm{mm}$ increase in size of residual tumor in at least one dimension when compared with postoperative MRI studies. Inter-observer reliability in the determination of $\mathrm{P} / \mathrm{R}$ is obtained via a Cohen $k$ value of 0.9. Judgment is made via consensus for equivocal cases. The preoperative MRI findings, including cavernous sinus invasion (Knosp classification) [20], extrasellar extension (Hardy's classification) [15], compression of the optic chiasm and the third ventricle, hydrocephalus, and 
intratumoral apoplexy or cystic change are determined on coronal T2WI and CE T1WI.

\section{Imaging acquisition}

Preoperative brain MRI images are acquired with a 1.5-T (Siemens, MAGNETOM Avanto) ( $n=18), 1.5-\mathrm{T}$ (GE Healthcare, Signa HDxt) $(n=10)$, or a 3-T (GE Healthcare, Discovery MR750) (n=6) MRI scanner equipped with an 8-channel head coil in each machine. Scanning protocols include axial and sagittal spin-echo T1-weighted imaging (T1WI), axial and coronal fast spin-echo T2-weighted imaging (T2WI), axial fluid-attenuated inversion recovery, axial T2*-weighted gradient-recalled echo, and coronal and sagittal contrastenhanced (CE) T1WI with fat saturation. Dynamic CE T1WI with a small field of view on the pituitary gland is also performed. For CE imaging, intravenous administration of $0.1 \mathrm{mmol} / \mathrm{kg}$ of body weight of gadobutrol or gadoterate meglumine is performed. Detailed imaging parameters in the MRI scanners are described in supplementary file 1 .

\section{Measurement of tumor diameter and volume}

Measurements of both tumor diameter and volume were obtained on coronal CE T1WI (Fig. 1) by using the freehand region of interest (ROI) tool on the Picture Archiving and Communication System (PACS) (INFINITT PACS; INFINITT Healthcare, Seoul, Republic of Korea) workstations. The preoperative maximal tumor diameter (MTD) is determined on coronal CE T1WI, and the STD is obtained by the only measurement of the solid tumor part. Preoperative total tumor volume (TTV) and postoperative residual volume (RV) are determined by manually calculating whole tumor areas in each coronal CE T1WI slice, and then compiling the volumes in the z-dimension using a semiautomated PACS measurement tool. The preoperative STV is obtained by the only measurement of solid tumor part without the involvement of intratumoral apoplexy, necrosis, or cystic change, which can be identified on coronal T2WI and CE T1WI (Figs. 1-3).
Fig. 1 Example of measurements of preoperative solid tumor diameter (STD) and solid tumor volume (STV) on coronal contrast-enhanced (CE) T1WI in large nonfunctioning pituitary adenomas (INFPA) and giant nonfunctioning pituitary adenomas (gNFPA). A Conventionally, both solid and cystic components were included in the measurement of maximal tumor diameter (MTD) (white arrow) (53 mm). B In contrast, STD was defined as a measurement of the largest solid tumor diameter (black arrow) $(39 \mathrm{~mm})$. C Both solid and cystic components were included in the calculation of total tumor volume (TTV) (blue area), which was $43.3 \mathrm{~cm}^{3}$. D Only solid tumor part was measured in STV (red area), which was $36.1 \mathrm{~cm}^{3}$

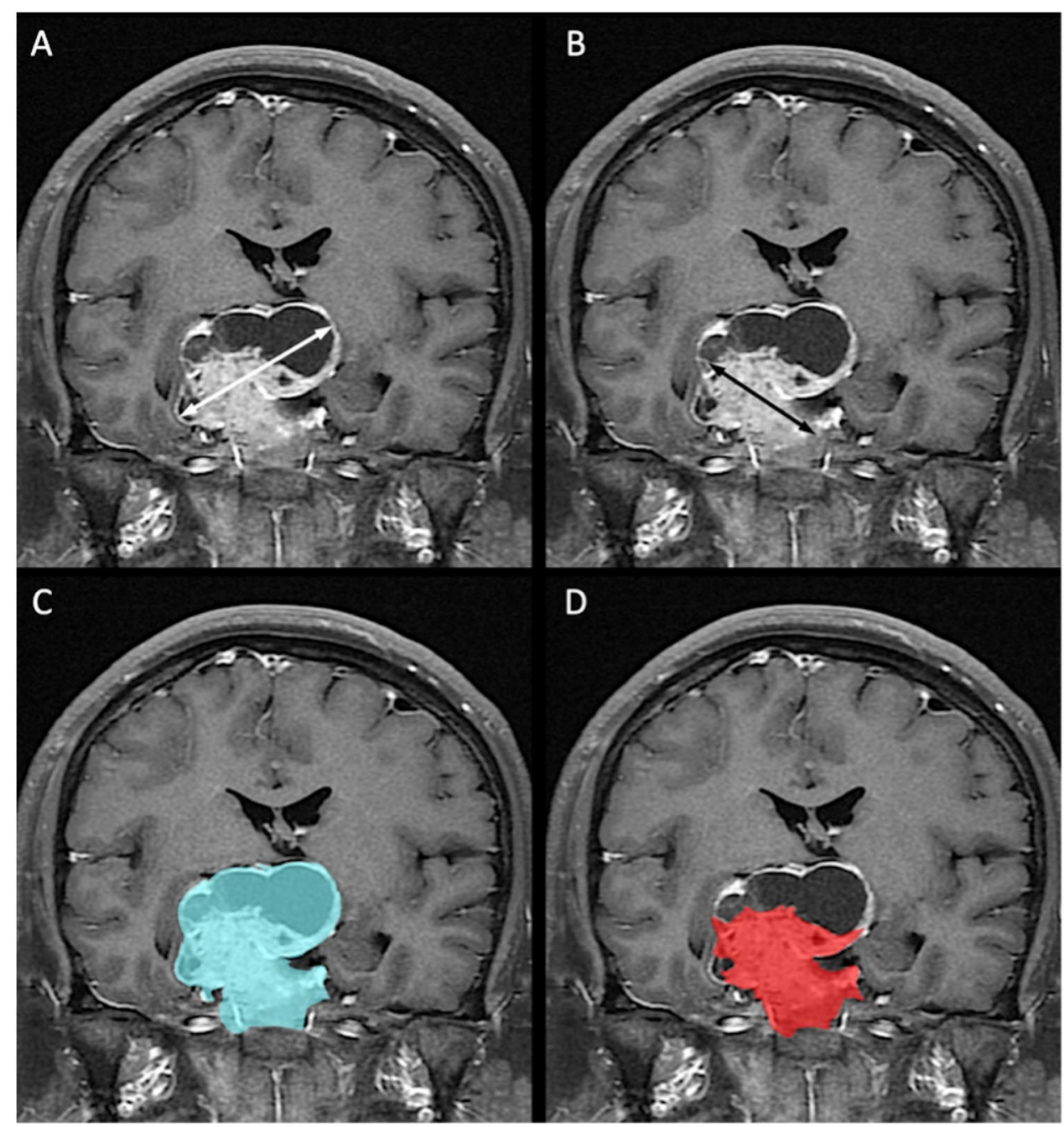


Table 1 Clinical and MRI characteristics of large and giant NFPA with and without P/R

\begin{tabular}{|c|c|c|c|}
\hline & $\mathrm{P} / \mathrm{R}(n=23)$ & Non-P/R $(n=11)$ & $p$ \\
\hline Number & 23 & 11 & \\
\hline Gender & & & 0.262 \\
\hline Male & $16(69.6 \%)$ & $5(45.5 \%)$ & \\
\hline Female & $7(30.4 \%)$ & $6(54.5 \%)$ & \\
\hline Age & $53(45.5,60.5)$ & $45(20.5,69.5)$ & 0.143 \\
\hline \multicolumn{4}{|l|}{ Clinical symptoms } \\
\hline Visual disturbance & $22(95.7 \%)$ & $10(90.9 \%)$ & 1 \\
\hline Headache & $9(39.1 \%)$ & $5(45.5 \%)$ & 1 \\
\hline Symptoms of sex hormones & $3(13 \%)$ & $1(9.1 \%)$ & 1 \\
\hline Incidental & $1(4.3 \%)$ & 0 & 1 \\
\hline Hypopituitarism & & & 0.925 \\
\hline Single & $5(21.7 \%)$ & $2(18.2 \%)$ & \\
\hline Multiple & $5(21.7 \%)$ & $2(18.2 \%)$ & \\
\hline Hyperprolactinemia $(<100 \mathrm{ng} / \mathrm{mL})$ & $8(34.8 \%)$ & $5(45.5 \%)$ & 0.709 \\
\hline Cavernous sinus invasion (Knosp grade 3-4) & $11(47.8 \%)$ & $4(36.4 \%)$ & 0.715 \\
\hline Extrasellar extension (Hardy's grade 3-4) & $12(52.2 \%)$ & $5(45.5 \%)$ & 0.714 \\
\hline Compression of optic chiasm & $22(95.7 \%)$ & $11(100 \%)$ & 1 \\
\hline Compression of $3^{\text {rd }}$ ventricle & $22(95.7 \%)$ & $9(81.8 \%)$ & 0.239 \\
\hline Hydrocephalus & $2(8.7 \%)$ & $1(9.1 \%)$ & 1 \\
\hline Apoplexy or cystic change & $11(47.8 \%)$ & $9(81.8 \%)$ & 0.076 \\
\hline Successful chiasmatic decompression & $7(30.4 \%)$ & $7(63.6 \%)$ & 0.135 \\
\hline Gross-total resection (GTR) & 0 & $2(18.2 \%)$ & 0.098 \\
\hline \multicolumn{4}{|l|}{ Preoperative tumor size } \\
\hline Maximal tumor diameter (MTD) (mm) & $38(33.5,42.5)$ & $36(28.5,43.5)$ & 0.326 \\
\hline Total tumor volume (TTV) $\left(\mathrm{cm}^{3}\right)$ & $14.1(7.5,20.7)$ & $10.5(4.6,16.4)$ & 0.344 \\
\hline Solid tumor diameter (STD) (mm) & $36(29.5,42.5)$ & $21(10,32)$ & $0.009 *$ \\
\hline Solid tumor volume $(\mathrm{STV})\left(\mathrm{cm}^{3}\right)$ & $12.7(5.7,19.7)$ & $6.3(3.7,16.8)$ & $0.007^{*}$ \\
\hline Residual volume $\left(\mathrm{cm}^{3}\right)$ & $5.9(0.5,11.3)$ & $3.9(1.0,6.9)$ & 0.082 \\
\hline Extent of resection (EOR) (\%) & $47(27,67)$ & $81(36,89)$ & 0.053 \\
\hline Follow up time (month) & $41(20,62)$ & $29(12,46)$ & 0.098 \\
\hline
\end{tabular}

Continuous variables were presented as median and interquartile range (IQR)

*Statistical difference $(p<0.05)$ in chi-square or Mann-Whitney $U$ tests

\section{Statistical analysis}

Statistical analyses were performed using SPSS for Windows (V.24.0, IBM, Chicago, IL, USA). For evaluating clinical parameters and MR imaging features, chi-square (or Fisher exact test) and Mann-Whitney $U$ tests are performed for categorical and continuous data respectively. The receiver operating characteristic (ROC) curve of STD, MTD, STV, and TTV for prediction of P/R was performed, and sensitivity, specificity, area under ROC (AUC), and optimal cutoff value were obtained. Further, Kaplan-Meier analyses based on cutoff values of STD and STV were used to evaluate the progression/ recurrence-free survival (PFS), and the log-rank test was used to assess the significance. Cox proportional hazard regression model with univariate and multivariate analysis was performed to determine independent factors of P/R. Variables with a $p$ value $<0.05$ in univariate analysis were brought forward to the multivariate analysis. For all statistical analyses, $p$ values $<0.05$ were considered statistically significant.

The inter-observer reliabilities in the categorical and continuous data were determined using the Cohen $k$ coefficient and intraclass correlation coefficient (ICC), respectively. The Cohen $k$ coefficient and ICC were interpreted using the methods described by Landis et al. [22]. Both Cohen $k$ coefficient and ICC with values between 0.8 and 1 were obtained, indicating almost perfect agreement. Due to almost perfect reproducibility in the ICC, the subsequent statistical evaluation of continuous data was performed using the mean value calculated from both readers. 


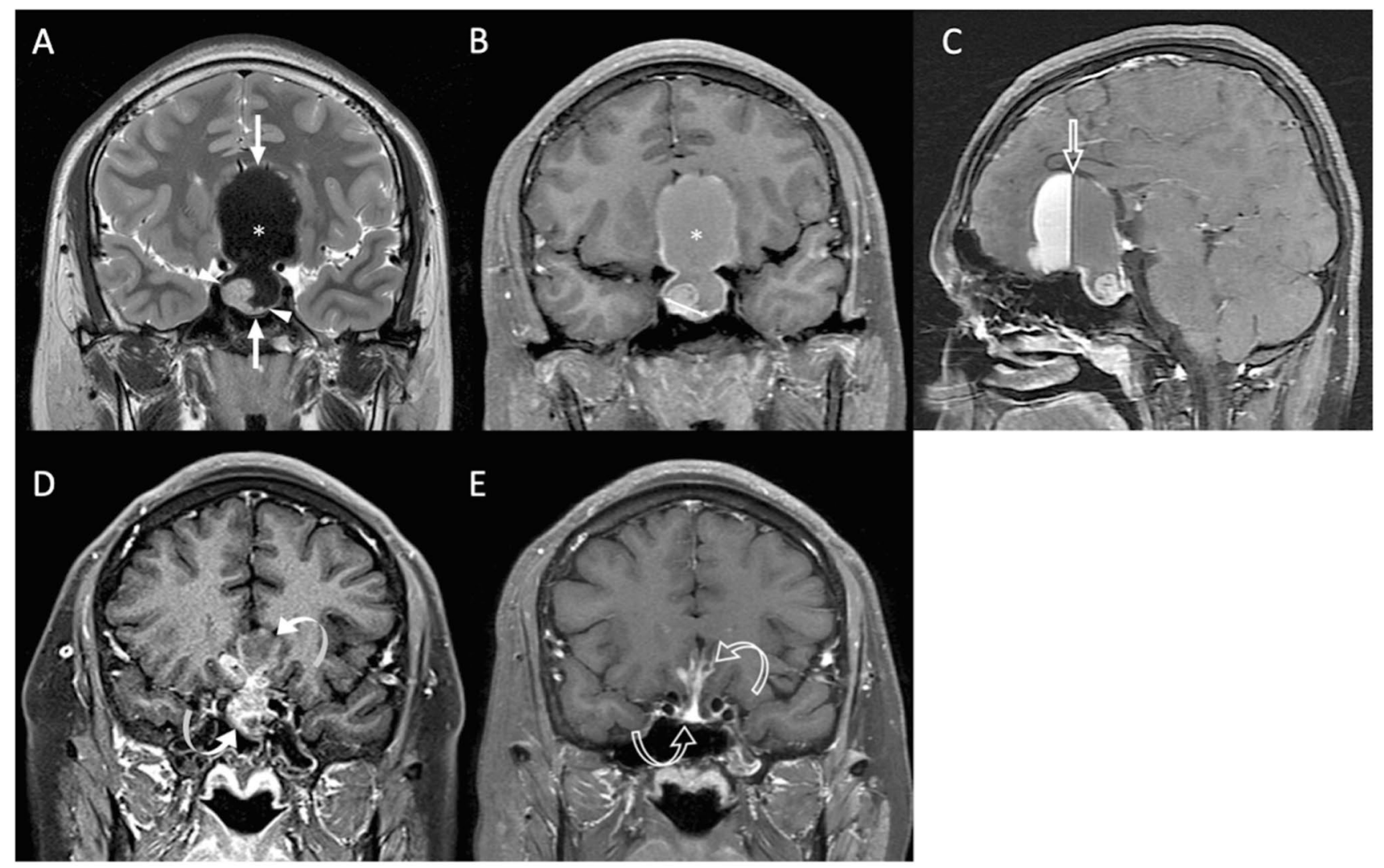

Fig. 2 An 18-year-old male patient with blurred vision and pathologically confirmed NFPA. A Coronal T2WI (A) shows a gNFPA $(>40 \mathrm{~mm}$ ) (white arrows) with upward suprasellar extension, causing compression of the optic chiasm and the third ventricle (cannot be seen). Intratumoral apoplexy (white star) and solid tumor part (arrowheads) were observed. B The STD (white double-headed arrow) measured on coronal CE T1WI was $15 \mathrm{~mm}$, and the STV was 1.6

\section{Results}

\section{Clinical data and MRI features}

The clinical data and MRI findings are summarized in Table 1. P/R is diagnosed in $23(23 / 34,67.6 \%)$ patients. Large preoperative STD and STV are more frequently observed in the $\mathrm{P} / \mathrm{R}$ group $(p<0.05)$ (Figs. 2 and 3$)$. In univariate Cox proportional hazards analysis (Table 2 ), significantly larger STD/STV and lesser EOR were observed in the P/R group $(p<0.05)$. Further, large STV is a risk factor for $\mathrm{P} / \mathrm{R}(p<0.05)$ with a hazard ratio of 30.79 in multivariate analysis (Table 2 ).

\section{ROC and Kaplan-Meier analyses in solid tumor size}

The median follow-up duration for all patients was 47.6 months. In 23 patients with $\mathrm{P} / \mathrm{R}$, the median time to $\mathrm{P} / \mathrm{R}$ is 25.2 months. The sensitivity, specificity, AUC, and optimal cutoff points of the STD and STV for differentiation between the $\mathrm{P} / \mathrm{R}$ and non-P/R groups are summarized $\mathrm{cm}^{3}$. In contrast, the measured MTD and TTV were $61 \mathrm{~mm}$ and 43.3 $\mathrm{cm}^{3}$. C Sagittal CE T1WI showed intratumoral fluid-fluid level (open arrow) due to apoplexy. D Subtotal tumor resection via transsphenoidal approach (TSA) was performed, and the residual tumor (curved arrows) was observed. E Gradual shrinkage of residual tumor (open curved arrows) without recurrence was observed until 71 months after surgery

in Table 3. The cutoff points for the STD and STV ratio were $26 \mathrm{~mm}$ and $7.6 \mathrm{~cm}^{3}$, respectively. An AUC of 0.78 , $0.61,0.79$, and 0.60 were obtained for the STD, MTD, STV, and TTV respectively (Fig. 4). When comparing the tumor $\mathrm{P} / \mathrm{R}$ trends in Kaplan-Meier analysis, patients with larger STD (more than the cutoff value of $26 \mathrm{~mm}$ ) and larger STV (more than the cutoff value of $7.6 \mathrm{~cm}^{3}$ ) exhibited shorter PFS $(p<0.05)$ (Fig. 5).

\section{Discussion}

The purpose of this study was to analyze preoperative solid tumor size in predicting P/R of INFPA and gNFPA after resection. The results showed that large STD and STV are significantly associated with $\mathrm{P} / \mathrm{R}$. Although the risk factors for the recurrence of NFPA have been previously reported, the present results are the first to offer quantitative cutoff points of preoperative solid tumor size for the prediction of $\mathrm{P} / \mathrm{R}$ in INFPA and gNFPA. 

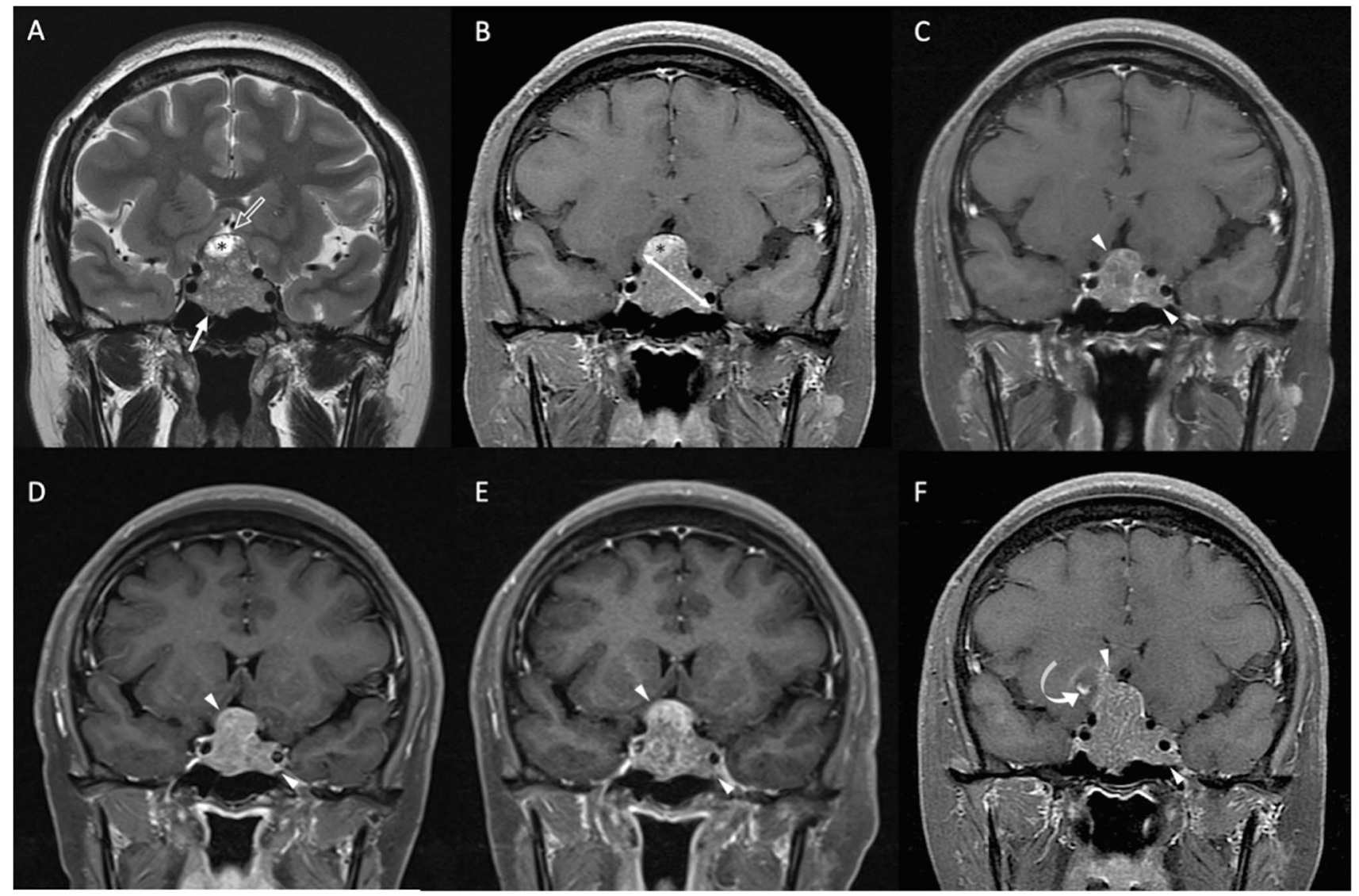

Fig. 3 A 37-year-old female patient with blurred vision, amenorrhea, and pathologically confirmed NFPA. A Coronal T2WI shows a INFPA (>30 mm) tumor (white arrow) with upward suprasellar extension, causing compression of the optic chiasm and the third ventricle (open arrow indicates an area of the optic chiasm and third ventricle). Focal intratumoral cystic change (black star) was observed. B The STD (white double-headed arrow) measured on coronal CE

Although most NFPA are benign pituitary adenomas, $12-46 \%$ of them may show early $\mathrm{P} / \mathrm{R}$ within 5 years after surgical resection $[6,7,40]$. According to 2017 WHO classification [27], tumor invasion and tumor proliferation index (Ki-67 and mitotic count) are associated with aggressive clinical behavior in NFPA. However, the definition of tumor invasion for NFPA was not clear in the WHO criteria and hence cannot be estimated if no corresponding information from MRI studies is considered [40, 44]. In the past 30 years, several meta-analyses consistently reported higher recurrence rates in NFPA than in secreting PA [6, 33, 37, 40]. Roelfsema et al. [40] showed that postoperative hormone concentration is an important predictor for $\mathrm{P} / \mathrm{R}$ in functioning PA; however, no specific predictor is identified for NFPA. In contrast to functioning PA, for which biochemical markers often suggest tumor recurrence before the visible tumor is detected on imaging, tumor remission or recurrence in NFPA is mainly determined by MR imaging [29].
T1WI was $29 \mathrm{~mm}$, and the STV was $8.8 \mathrm{~cm}^{3}$. C Subtotal tumor resection via TSA was performed, and the diameter of the residual tumor (arrowheads) was $28 \mathrm{~mm}$. D, E, F Progressive enlargement of the residual tumor (arrowheads) was observed at $\mathbf{D} 6$ months (diameter of $31 \mathrm{~mm}$ ), E 13 months (diameter of $36 \mathrm{~mm}$ ), and F 56 months (diameter of $43 \mathrm{~mm}$ ) after surgical resection. F Focal apoplexy (curved arrow) was also observed in the recurrent tumor (arrowheads)

Some MR imaging features for the prediction of EOR and clinical outcomes in INFPA and gNFPA had been reported $[17,18,36]$. Invasion of the cavernous sinus, maximum tumor diameter, and absence of tumor apoplexy were associated with an unfavorable surgical outcome in NFPA [28]. Invasion of the cavernous sinus is significantly associated with incomplete resection and residual tumor [2]. In contrast, more complete resection and less tumor recurrence could be achieved in NFPA with apoplexy [1]. This may explain why tumor recurrence is not significantly associated with the largest tumor diameter and total tumor volume, which are measured on both solid and apoplexy/cystic components of NFPA. RECIST is based on one-dimensional measurement of tumor size and is the gold standard for the evaluation of therapeutic response in solid tumors. However, a modified RECIST for hepatocellular carcinoma was developed by Lencioni et al. [26] based on the concept that a viable tumor should be defined as only intratumoral 
Table 2 Cox proportional hazards analysis for $\mathrm{P} / \mathrm{R}$

\begin{tabular}{|c|c|c|c|c|}
\hline & Univariate analysis & & Multivariate analysis & \\
\hline & $\begin{array}{l}\mathrm{HR}(95 \% \mathrm{CI}) \text { for } \mathrm{P} / \mathrm{R} \\
(n=34)\end{array}$ & $p$ & $\begin{array}{l}\mathrm{HR}(95 \% \mathrm{CI}) \text { for } \mathrm{P} / \mathrm{R} \\
(n=34)\end{array}$ & $p$ \\
\hline Sex (fraction male) & $2.74(0.62,12.08)$ & 0.182 & & \\
\hline Age (years) & $1.04(0.99,1.09)$ & 0.476 & & \\
\hline Hyperprolactinemia & $0.64(0.15,2.77)$ & 0.550 & & \\
\hline Cavernous sinus invasion (Knosp grade 3-4) & $1.60(0.37,7.02)$ & 0.530 & & \\
\hline Extrasellar extension (Hardy's grade 3-4) & $1.31(0.31,5.53)$ & 0.714 & & \\
\hline Compression of 3 rd ventricle & $4.89(0.39,60.92)$ & 0.218 & & \\
\hline Apoplexy or cystic change & $0.20(0.04,1.16)$ & 0.073 & & \\
\hline Successful chiasmatic decompression & $0.25(0.06,1.14)$ & 0.073 & & \\
\hline Maximal tumor diameter $(\mathrm{mm})$ & $1.30(0.55,3.07)$ & 0.545 & & \\
\hline Total tumor volume $\left(\mathrm{cm}^{3}\right)$ & $1.02(0.96,1.07)$ & 0.584 & & \\
\hline STD > 26 mm (cutoff value) & $38.5(3.67,403.93)$ & $0.002 *$ & & \\
\hline STV $>7.6 \mathrm{~cm}^{3}$ (cutoff value) & $28(3.92,199.94)$ & $0.001 *$ & $30.79(2.25,420.76)$ & $0.01 *$ \\
\hline Residual volume $\left(\mathrm{cm}^{3}\right)$ & $1.04(0.97,1.13)$ & 0.276 & & \\
\hline Extent of resection (EOR) (\%) & $0.97(0.94,1.00)$ & $0.041^{*}$ & $1.00(0.96,1.05)$ & 0.866 \\
\hline Follow up time (month) & $1.02(0.99,1.05)$ & 0.212 & & \\
\hline
\end{tabular}

*Statistical difference $(p<0.05)$ in Cox proportional hazard regression analysis

Table 3 ROC analysis of STD and STV for differentiating large and giant NFPA with and without $\mathrm{P} / \mathrm{R}$

\begin{tabular}{llllll}
\hline$(n=34)$ & Sensitivity & Specificity & AUC & Cutoff value & $p$ \\
\hline Solid tumor diameter (STD) & 0.96 & 0.64 & 0.78 & $26 \mathrm{~mm}$ & $0.011^{*}$ \\
Solid tumor volume (STV) & 0.91 & 0.73 & 0.79 & $7.6 \mathrm{~cm}^{3}$ & $0.008^{*}$ \\
\hline
\end{tabular}

* Statistical difference $(p<0.05)$ in ROC analysis
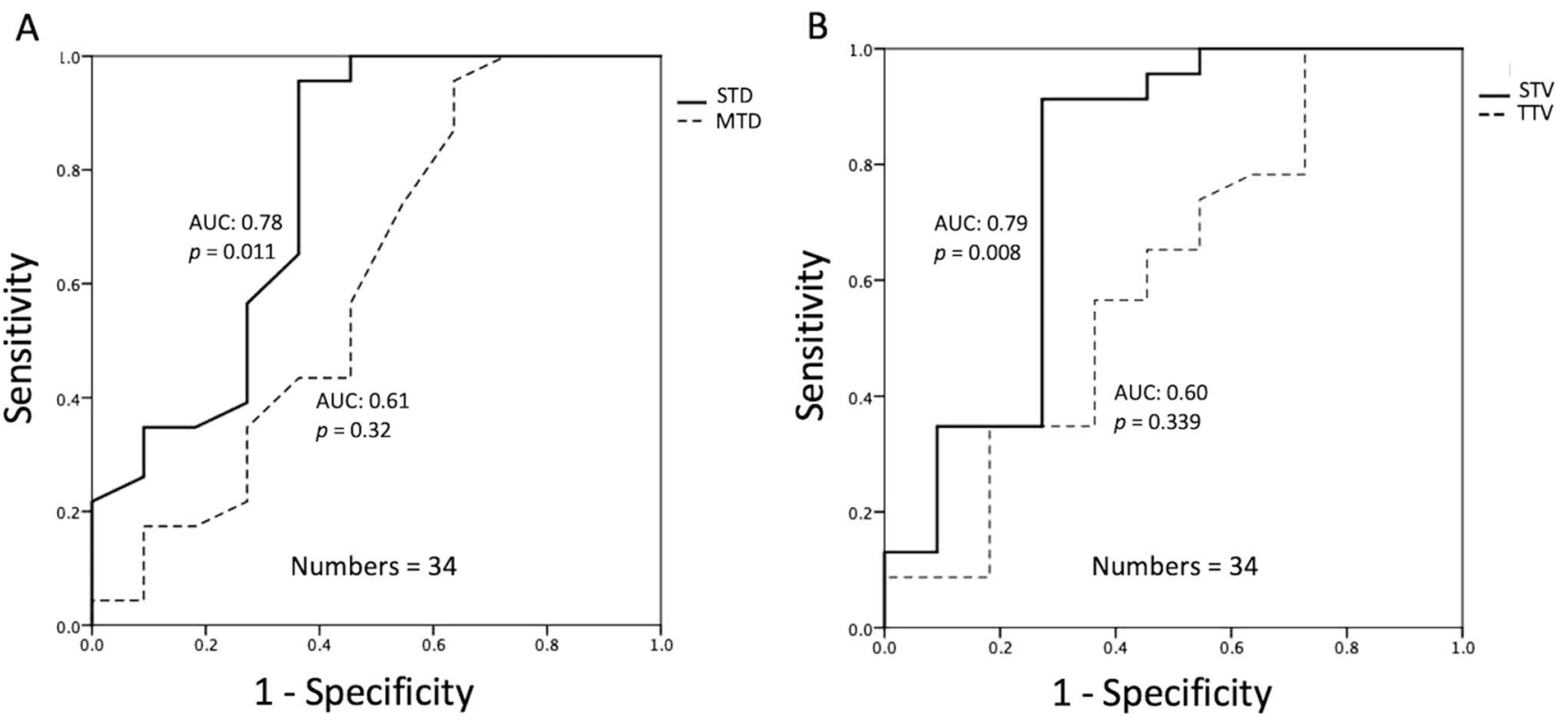

Fig. 4 Receiver operating characteristic (ROC) curves of preoperative STD, MTD, STV, and TTV for prediction of P/R in INFPA and gNFPA. AUC values of 0.78 and 0.79 with cutoff points of $26 \mathrm{~mm}$ and $7.6 \mathrm{~cm}^{3}$ were observed in STD (A) and STV (B), respectively 
A

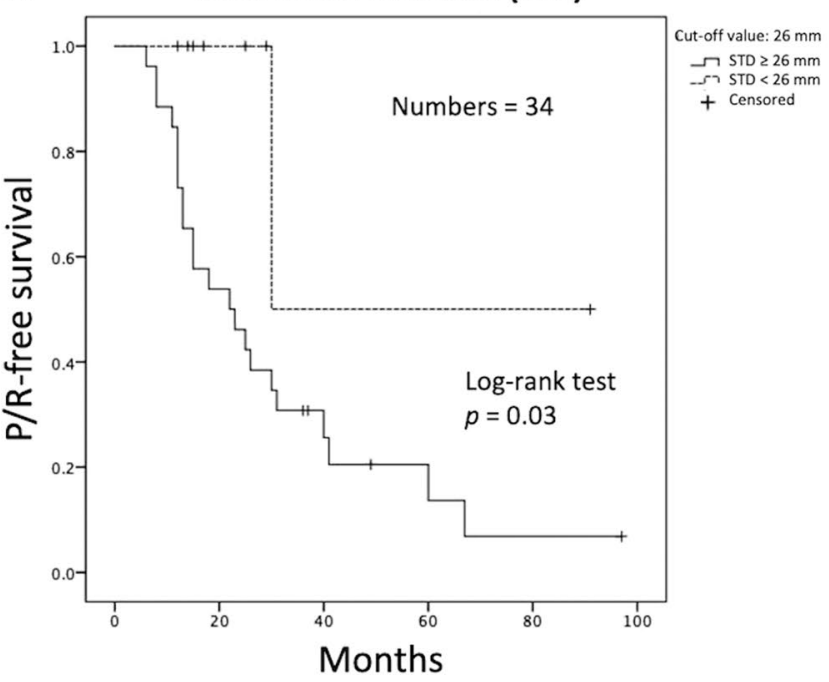

B Solid tumor volume (STV)

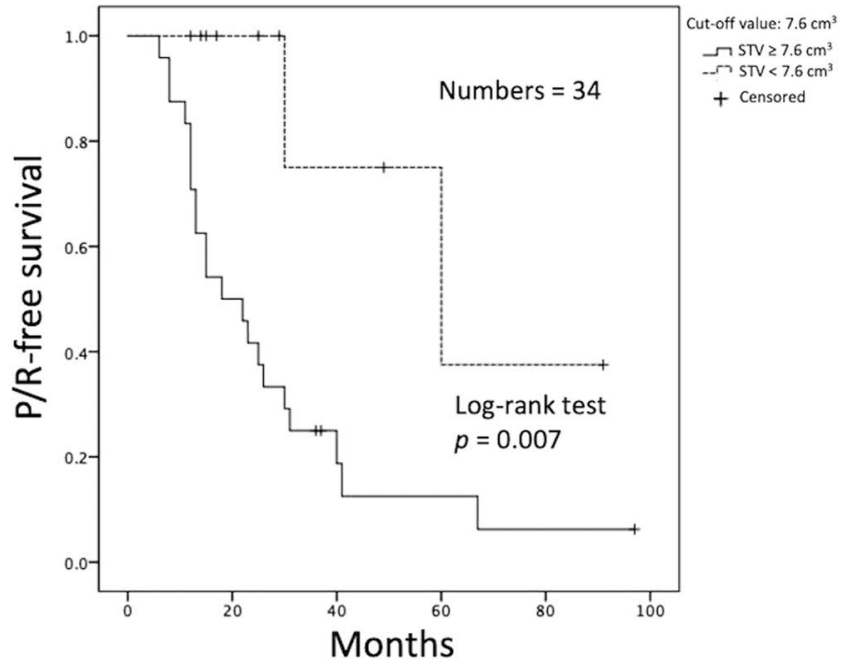

Fig. 5 Kaplan-Meier survival curves showing significantly different $(p<0.05)$ progression/recurrence $(\mathrm{P} / \mathrm{R})$-free survival based on cutoff points of preoperative STD (A) and STV (B) in INFPA and gNFPA

enhancing solid tumor part [3]. Lee et al. [24] reported that measurement of only solid tumor mass offers a better assessment of treatment response as compared with conventional RECIST in patients receiving targeted therapies for lung cancer. Similarly, association between solid tumor size and recurrence rate in INFPA and gNFPA were observed in our study. On the other hand, low apparent diffusion coefficient value (diffusion restriction) is associated with recurrence in NFPA [21, 42]. Recently, quantitative MRI-based radiomics is also used for the evaluation of tumor behaviors in NFPA [46]. However, these parameters need to be measured on advanced MRI sequences and analyzed with complex statistical algorithms. The concept of simple and straight morphologic measurement focusing on solid tumor size for the prediction of clinical outcomes in NFPA is first mentioned in our study. The results offer quantitative, fast, and consistent measurement for neurosurgeons, radiologists, and clinical physicians in the evaluation of INFPA and gNFPA.

EOR is a significant determining factor in the rate of recurrence in NFPA [2, 6, 29]. As the residual tumor due to incomplete surgical resection exists in most large and giant NFPA after surgery $[18,36]$, the issue of tumor recurrence is particularly important in this subgroup. Lee et al. [25] reported a recurrence rate of $8.2 \%$ and $58.3 \%$ in patients receiving GTR and STR, respectively. Maletkovic et al. [29] revealed that postoperative residual tumor confers a tenfold increased risk of recurrence in NFPA. Similarly, the association between EOR and $\mathrm{P} / \mathrm{R}$ was observed in univariate regression analysis in our study. No statistical difference in the multivariate analysis may be explained by the small sample size and the association between EOR and solid tumor size.
It is known that postoperative adjuvant RT or stereotactic radiosurgery (SRS) is highly effective in preventing $P / R$ in PA [23, 31]. Lee et al. [23] showed that empirical SRS was superior to progression-guided SRS for NFPA after subtotal resection. Although adjuvant RT and SRS may increase risks of radiation-induced complications such as hypopituitarism, neurocognitive dysfunction, cerebrovascular disease, and secondary brain tumors, the overall rate of serious complications is low [11, 14, 17, 32]. Progressive and irreversible hypopituitarism is the most commonly reported late complication, up to $20-30 \%$ at 5 years after treatment [17]. Since most NFPA are benign tumors, prediction of tumor recurrence offers clinically valuable information for treatment options. For patients with high possibilities of P/R, aggressive surgical resection combined with postoperative adjuvant RT and close MRI follow-up should be considered. In contrast, the surgery would aim to relieve clinical symptoms by decreasing tumor mass effects for patients with lower possibilities of tumor recurrence. Patients receiving adjuvant RT before $\mathrm{P} / \mathrm{R}$ were excluded from our study because RT may affect the independent prediction of the preoperative MR imaging analysis for $\mathrm{P} / \mathrm{R}$.

The results of the current study propose cutoff values of solid tumor size for the preoperative prediction of $\mathrm{P} / \mathrm{R}$ in NFPA. However, there are still several limitations in this study. Selection bias may exist due to its retrospective nature. As in other ROI-based studies, subjective freehand ROIs might influence the accuracy of the tumor size measurements. The small sample size may limit statistical power to detect potential associations between clinical or imaging parameters and P/R. Finally, there is a lack of 
complete histopathologic findings such as Ki-67 (MIB-1) and genomic signature for correlation in this retrospective study.

\section{Conclusions}

INFPA and gNFPA with larger solid tumor part were associated with higher possibilities of recurrence. The preoperative solid tumor diameter and volume for the prediction of $\mathrm{P} / \mathrm{R}$ offer clinically useful information for the planning of NFPA treatment, including the extent of surgical resection, implementation of post-operative adjuvant RT, and the MR imaging follow-up strategy.

Supplementary Information The online version contains supplementary material available at https://doi.org/10.1007/s10143-021-01662-7.

Author contribution Conceived and designed the experiments: CCK. Performed the experiments: CCK. Analyzed the data: CCK, CHC, TYC, SWL. Contributed reagents/materials/analysis tools: CHC, TYC, SWL, TCW. Wrote the paper: CCK. Critically revised the article: JHC, YTK.

Funding This work was supported by the Ministry of Science and Technology (MOST) in Taiwan (MOST 109-2314-B-384-010-MY2). The funders had no role in study design, data collection and analysis, decision to publish, or preparation of the manuscript.

\section{Code availability Not applicable}

Data availability The original contributions presented in the study are included in the article and supplementary material. Further inquiries can be directed to the corresponding author.

\section{Declarations}

Ethics approval The studies involving human participants were reviewed and approved by Chi Mei Medical Center Institutional Review Board (IRB no. 10902-009).

Consent to participate Written informed consent for participation was not required for this retrospective study in accordance with the national legislation and the institutional requirement.

Consent for publication Written informed consent for publication was not required for this retrospective study in accordance with the national legislation and the institutional requirement.

Conflict of interest The authors declare no competing interests.

Open Access This article is licensed under a Creative Commons Attribution 4.0 International License, which permits use, sharing, adaptation, distribution and reproduction in any medium or format, as long as you give appropriate credit to the original author(s) and the source, provide a link to the Creative Commons licence, and indicate if changes were made. The images or other third party material in this article are included in the article's Creative Commons licence, unless indicated otherwise in a credit line to the material. If material is not included in the article's Creative Commons licence and your intended use is not permitted by statutory regulation or exceeds the permitted use, you will need to obtain permission directly from the copyright holder. To view a copy of this licence, visit http://creativecommons.org/licenses/by/4.0/.

\section{References}

1. Boxerman JL, Rogg JM, Donahue JE, Machan JT, Goldman MA, Doberstein CE (2010) Preoperative MRI evaluation of pituitary macroadenoma: imaging features predictive of successful transsphenoidal surgery. AJR Am J Roentgenol 195:720-728. https:// doi.org/10.2214/ajr.09.4128

2. Brochier S, Galland F, Kujas M, Parker F, Gaillard S, Raftopoulos C, Young J, Alexopoulou O, Maiter D, Chanson P (2010) Factors predicting relapse of nonfunctioning pituitary macroadenomas after neurosurgery: a study of 142 patients. Eur J Endocrinol 163:193-200. https://doi.org/10.1530/eje-10-0255

3. Bruix J, Sherman M, Llovet JM, Beaugrand M, Lencioni R, Burroughs AK, Christensen E, Pagliaro L, Colombo M, Rodés J (2001) Clinical management of hepatocellular carcinoma. Conclusions of the Barcelona-2000 EASL conference. European Association for the Study of the Liver. J Hepatol 35:421-430. https:// doi.org/10.1016/s0168-8278(01)00130-1

4. Cappabianca P, Cavallo LM, Esposito F, De Divitiis O, Messina A, De Divitiis E (2008) Extended endoscopic endonasal approach to the midline skull base: the evolving role of transsphenoidal surgery. Adv Tech Stand Neurosurg 33:151-199. https://doi.org/ 10.1007/978-3-211-72283-1_4

5. Chabot JD, Chakraborty S, Imbarrato G, Dehdashti AR (2015) Evaluation of outcomes after endoscopic endonasal surgery for large and giant pituitary macroadenoma: a retrospective review of 39 consecutive patients. World Neurosurg 84:978-988. https:// doi.org/10.1016/j.wneu.2015.06.007

6. Chen Y, Wang CD, Su ZP, Chen YX, Cai L, Zhuge QC, Wu ZB (2012) Natural history of postoperative nonfunctioning pituitary adenomas: a systematic review and meta-analysis. Neuroendocrinology 96:333-342. https://doi.org/10.1159/000339823

7. Cortet-Rudelli C, Bonneville JF, Borson-Chazot F, Clavier L, CocheDequéant B, Desailloud R, Maiter D, Rohmer V, Sadoul JL, Sonnet E, Toussaint P, Chanson P (2015) Post-surgical management of non-functioning pituitary adenoma. Ann Endocrinol (Paris) 76:228-238. https://doi.org/10.1016/j.ando.2015.04.003

8. Cusimano MD, Kan P, Nassiri F, Anderson J, Goguen J, Vanek I, Smyth HS, Fenton R, Muller PJ, Kovacs K (2012) Outcomes of surgically treated giant pituitary tumours. Can J Neurol Sci 39:446-457. https://doi.org/10.1017/s0317167100013950

9. Dekkers OM, Hammer S, de Keizer RJ, Roelfsema F, Schutte PJ, Smit JW, Romijn JA, Pereira AM (2007) The natural course of non-functioning pituitary macroadenomas. Eur J Endocrinol 156:217-224. https://doi.org/10.1530/eje.1.02334

10. Eisenhauer EA, Therasse P, Bogaerts J, Schwartz LH, Sargent D, Ford R, Dancey J, Arbuck S, Gwyther S, Mooney M, Rubinstein L, Shankar L, Dodd L, Kaplan R, Lacombe D, Verweij J (2009) New response evaluation criteria in solid tumours: revised RECIST guideline (version 1.1). Eur J Cancer 45:228-247. https:// doi.org/10.1016/j.ejca.2008.10.026

11. Erfurth EM, Bülow B, Svahn-Tapper G, Norrving B, Odh K, Mikoczy Z, Björk J, Hagmar L (2002) Risk factors for cerebrovascular deaths in patients operated and irradiated for pituitary tumors. J Clin Endocrinol Metab 87:4892-4899. https://doi.org/ 10.1210/jc.2002-020526

12. Ezzat S, Asa SL, Couldwell WT, Barr CE, Dodge WE, Vance ML, McCutcheon IE (2004) The prevalence of pituitary adenomas: a 
systematic review. Cancer 101:613-619. https://doi.org/10.1002/ cncr.20412

13. Ferrante E, Ferraroni M, Castrignanò T, Menicatti L, Anagni M, Reimondo G, Del Monte P, Bernasconi D, Loli P, FaustiniFustini M, Borretta G, Terzolo M, Losa M, Morabito A, Spada A, Beck-Peccoz P, Lania AG (2006) Non-functioning pituitary adenoma database: a useful resource to improve the clinical management of pituitary tumors. Eur J Endocrinol 155:823829. https://doi.org/10.1530/eje.1.02298

14. Hahn CA, Zhou SM, Raynor R, Tisch A, Light K, Shafman T, Wong T, Kirkpatrick J, Turkington T, Hollis D, Marks LB (2009) Dose-dependent effects of radiation therapy on cerebral blood flow, metabolism, and neurocognitive dysfunction. Int J Radiat Oncol Biol Phys 73:1082-1087. https://doi.org/10. 1016/j.ijrobp.2008.05.061

15. Hardy J (1969) Transphenoidal microsurgery of the normal and pathological pituitary. Clin Neurosurg 16:185-217. https://doi. org/10.1093/neurosurgery/16.cn_suppl_1.185

16. Hong JW, Lee MK, Kim SH, Lee EJ (2010) Discrimination of prolactinoma from hyperprolactinemic non-functioning adenoma. Endocrine 37:140-147. https://doi.org/10.1007/ s12020-009-9279-7

17. Iglesias P, Rodríguez Berrocal V, Díez JJ (2018) Giant pituitary adenoma: histological types, clinical features and therapeutic approaches. Endocrine 61:407-421. https://doi.org/10.1007/ s12020-018-1645-x

18. Juraschka K, Khan OH, Godoy BL, Monsalves E, Kilian A, Krischek B, Ghare A, Vescan A, Gentili F, Zadeh G (2014) Endoscopic endonasal transsphenoidal approach to large and giant pituitary adenomas: institutional experience and predictors of extent of resection. J Neurosurg 121:75-83. https://doi.org/ 10.3171/2014.3.Jns 131679

19. Karki M, Sun J, Yadav CP, Zhao B (2017) Large and giant pituitary adenoma resection by microscopic trans-sphenoidal surgery: surgical outcomes and complications in 123 consecutive patients. J Clin Neurosci 44:310-314. https://doi.org/10. 1016/j.jocn.2017.07.015

20. Knosp E, Steiner E, Kitz K, Matula C (1993) Pituitary adenomas with invasion of the cavernous sinus space: a magnetic resonance imaging classification compared with surgical findings. Neurosurgery 33:610-617. https://doi.org/10.1227/00006 123-199310000-00008

21. Ko CC, Chen TY, Lim SW, Kuo YT, Wu TC, Chen JH (2019) Prediction of recurrence in solid nonfunctioning pituitary macroadenomas: additional benefits of diffusion-weighted MR imaging. J Neurosurg 132:351-359. https://doi.org/10.3171/ 2018.10.Jns 181783

22. Landis JR, Koch GG (1977) The measurement of observer agreement for categorical data. Biometrics 33:159-174

23. Lee CC, Yang HC, Chen CJ, Lin CJ, Wu HM, Chung WY, Shiau CY, Guo WY, Pan DH (2019) Empirical versus progressionguided stereotactic radiosurgery for non-functional pituitary macroadenomas after subtotal resection. J Neurooncol 142:291297. https://doi.org/10.1007/s11060-019-03095-1

24. Lee HY, Lee KS, Ahn MJ, Hwang HS, Lee JW, Park K, Ahn JS, Kim TS, Yi CA, Chung MJ (2011) New CT response criteria in non-small cell lung cancer: proposal and application in EGFR tyrosine kinase inhibitor therapy. Lung Cancer 73:63-69. https://doi.org/10.1016/j.lungcan.2010.10.019

25. Lee MH, Lee JH, Seol HJ, Lee JI, Kim JH, Kong DS, Nam DH (2016) Clinical concerns about recurrence of non-functioning pituitary adenoma. Brain Tumor Res Treat 4:1-7. https://doi. org/10.14791/btrt.2016.4.1.1

26. Lencioni R, Llovet JM (2010) Modified RECIST (mRECIST) assessment for hepatocellular carcinoma. Semin Liver Dis 30:52-60. https://doi.org/10.1055/s-0030-1247132
27. Lloyd RV, Osamura RY, Klöppel G, Rosai J (2017) WHO classification of tumours of endocrine organs. International Agency for Research on Cancer, France

28. Losa M, Mortini P, Barzaghi R, Ribotto P, Terreni MR, Marzoli SB, Pieralli S, Giovanelli M (2008) Early results of surgery in patients with nonfunctioning pituitary adenoma and analysis of the risk of tumor recurrence. J Neurosurg 108:525-532. https:// doi.org/10.3171/jns/2008/108/3/0525

29. Maletkovic J, Dabbagh A, Zhang D, Zahid A, Bergsneider M, Wang MB, Linetsky M, Salamon N, Yong WH, Vinters HV, Heaney AP (2019) Residual tumor confers a 10-fold increased risk of regrowth in clinically nonfunctioning pituitary tumors. J Endocr Soc 3:1931-1941. https://doi.org/10.1210/js. 2019-00163

30. Matsuyama J, Kawase T, Yoshida K, Hasegawa M, Hirose Y, Nagahisa S, Watanabe S, Sano H (2010) Management of large and giant pituitary adenomas with suprasellar extensions. Asian J Neurosurg 5:48-53

31. Minniti G, Flickinger J, Tolu B, Paolini S (2018) Management of nonfunctioning pituitary tumors: radiotherapy. Pituitary 21:154 161. https://doi.org/10.1007/s11102-018-0868-4

32. Minniti G, Traish D, Ashley S, Gonsalves A, Brada M (2005) Risk of second brain tumor after conservative surgery and radiotherapy for pituitary adenoma: update after an additional 10 years. J Clin Endocrinol Metab 90:800-804. https://doi.org/10.1210/jc. 2004-1152

33. Murad MH, Fernández-Balsells MM, Barwise A, GallegosOrozco JF, Paul A, Lane MA, Lampropulos JF, Natividad I, Perestelo-Pérez L, Ponce de León-Lovatón PG, Albuquerque FN, Carey J, Erwin PJ, Montori VM (2010) Outcomes of surgical treatment for nonfunctioning pituitary adenomas: a systematic review and meta-analysis. Clin Endocrinol (Oxf) 73:777-791. https://doi.org/10.1111/j.1365-2265.2010.03875.x

34. Müslüman AM, Cansever T, Yilmaz A, Kanat A, Oba E, Çavuşoğlu H, Sirinoğlu D, Aydın Y (2011) Surgical results of large and giant pituitary adenomas with special consideration of ophthalmologic outcomes. World neurosurgery 76:141-148; discussion 163-146. https://doi.org/10.1016/j.wneu.2011.02.009

35. Nishino M, Giobbie-Hurder A, Gargano M, Suda M, Ramaiya NH, Hodi FS (2013) Developing a common language for tumor response to immunotherapy: immune-related response criteria using unidimensional measurements. Clin Cancer Res 19:39363943. https://doi.org/10.1158/1078-0432.Ccr-13-0895

36. Nishioka H, Hara T, Nagata Y, Fukuhara N, Yamaguchi-Okada M, Yamada S (2017) Inherent tumor characteristics that limit effective and safe resection of giant nonfunctioning pituitary adenomas. World neurosurgery 106:645-652. https://doi.org/10.1016/j. wneu.2017.07.043

37. Pereira AM, Biermasz NR (2012) Treatment of nonfunctioning pituitary adenomas: what were the contributions of the last 10 years? A critical view. Ann Endocrinol (Paris) 73:111-116. https://doi.org/10.1016/j.ando.2012.04.002

38. Peto I, Abou-Al-Shaar H, White TG, Abunimer AM, Kwan K, Zavadskiy G, Wagner K, Black K, Eisenberg M, Bruni M, Dehdashti AR (2020) Sources of residuals after endoscopic transsphenoidal surgery for large and giant pituitary adenomas. Acta Neurochir (Wien) 162:2341-2351. https://doi.org/10.1007/ s00701-020-04497-1

39. Reddy R, Cudlip S, Byrne JV, Karavitaki N, Wass JA (2011) Can we ever stop imaging in surgically treated and radiotherapy-naive patients with non-functioning pituitary adenoma? Eur J Endocrinol 165:739-744. https://doi.org/10.1530/eje-11-0566

40. Roelfsema F, Biermasz NR, Pereira AM (2012) Clinical factors involved in the recurrence of pituitary adenomas after surgical remission: a structured review and meta-analysis. Pituitary 15:7183. https://doi.org/10.1007/s11102-011-0347-7 
41. Sanmillán JL, Torres-Diaz A, Sanchez-Fernández JJ, Lau R, Ciller C, Puyalto P, Gabarrós A (2017) Radiologic predictors for extent of resection in pituitary adenoma surgery. A Single-Center Study World neurosurgery 108:436-446. https://doi.org/10.1016/j.wneu.2017.09.017

42. Tamrazi B, Pekmezci M, Aboian M, Tihan T, Glastonbury CM (2017) Apparent diffusion coefficient and pituitary macroadenomas: pre-operative assessment of tumor atypia. Pituitary 20:195200. https://doi.org/10.1007/s11102-016-0759-5

43. Therasse P, Arbuck SG, Eisenhauer EA, Wanders J, Kaplan RS, Rubinstein L, Verweij J, Van Glabbeke M, van Oosterom AT, Christian MC, Gwyther SG (2000) New guidelines to evaluate the response to treatment in solid tumors. European Organization for Research and Treatment of Cancer, National Cancer Institute of the United States, National Cancer Institute of Canada. J Natl Cancer Inst 92:205-216. https://doi.org/10.1093/jnci/92.3.205

44. Trouillas J, Roy P, Sturm N, Dantony E, Cortet-Rudelli C, Viennet G, Bonneville JF, Assaker R, Auger C, Brue T, Cornelius A, Dufour H, Jouanneau E, François P, Galland F, Mougel F, Chapuis F, Villeneuve L, Maurage CA, Figarella-Branger D,
Raverot G, Barlier A, Bernier M, Bonnet F, Borson-Chazot F, Brassier G, Caulet-Maugendre S, Chabre O, Chanson P, Cottier JF, Delemer B, Delgrange E, Di Tommaso L, Eimer S, Gaillard S, Jan M, Girard JJ, Lapras V, Loiseau H, Passagia JG, Patey M, Penfornis A, Poirier JY, Perrin G, Tabarin A (2013) A new prognostic clinicopathological classification of pituitary adenomas: a multicentric case-control study of 410 patients with 8 years postoperative follow-up. Acta Neuropathol 126:123-135. https://doi. org/10.1007/s00401-013-1084-y

45. Wang S, Sa L, Wei L, Zhao L, Huang Y (2014) Analysis of operative efficacy for giant pituitary adenoma. BMC Surg 14:59. https:// doi.org/10.1186/1471-2482-14-59

46. Zhang Y, Ko CC, Chen JH, Chang KT, Chen TY, Lim SW, Tsui YK, Su MY (2020) Radiomics approach for prediction of recurrence in non-functioning pituitary macroadenomas. Front Oncol 10:590083. https://doi.org/10.3389/fonc. 2020.590083

Publisher's note Springer Nature remains neutral with regard to jurisdictional claims in published maps and institutional affiliations. 